Для цитирования: Мякотных В.С., Анохина М.В., Сиденкова А.П., Сердюк О.В., Мельник А.А. Перспективные терапевтические подходы к когнитивным расстройствам (роль пробиотиков в комплексном лечении): литературный обзор. Сибирский вестник психиатрии и наркологии. 2020; 4 (109): 73-81. https://doi.org/10.26617/1810-3111-2020-4(109)-73-81

\title{
Перспективные терапевтические подходы к когнитивным расстройствам (роль пробиотиков в комплексном лечении): литературный обзор
}

\author{
Мякотных В.С. ${ }^{1}$, Анохина М.B.', Сиденкова А.ח.', \\ Сердюк О.В.', Мельник А.А.' \\ ${ }^{1}$ ФГБОУ ВО «Уральский государственный медиџинский университет» Минздрава России \\ Россия, 620128, Екатеринбург, ул. Репина, 3 \\ ${ }^{2}$ ГБУЗ Свердловской области «Свердловская областная клиническая психиатрическая больница» \\ Россия, 620030, Екатеринбург, Сибирский тракт, 8 км
}

\section{PEЗЮME}

В статье представлен обзор современных научных отечественных и зарубежных публикаций, посвященных возможностям применения пробиотиков в терапии и профилактике возрастно-специфичной церебральной патологии. Высокая частота распространенности додементных когнитивных расстройств в контингенте лиц старших возрастных групп, значимый риск их трансформации в деменцию, ограниченные протекционные возможности классических терапевтических схем в совокупности определяют необходимость поиска современных стратегий помощи, направленных на снижение темпа старения ЦНС и предотвращение формирования его патологических форм. Патогенетическая многофакторность проблемы патологического старения ЦНС, современные знания о значительном вкладе в него механизмов нейровоспаления, дисфункциональности оси «микробиота - кишечник - мозг», потенциальная возможность коррекции состава микробиоты посредством введения пробиотиков - всё это позволяет рассматривать пробиотические препараты как перспективный терапевтический ресурс профилактики церебральной патологии. Цель исследования: выявление возможностей использования пробиотиков в профилактике и лечении заболеваний центральной нервной системы. Материалы исследования: научные публикации, посвященные освещению роли пробиотиков в комплексном лечении когнитивных расстройств. Применен общенаучный метод: анализ современной научной отечественной и зарубежной литературы по проблеме исследования, обобщение, сравнение, систематизация теоретических данных об опыте применения, оценка эффективности пробиотических средств в терапии когнитивных расстройств и проявления их протективного, ЦНС-ориентированного действия. Представленный анализ теоретических предпосылок применения пробиотиков при психических расстройствах, механизмов протективного действия пробиотиков на головной мозг, терапевтической эффективности применения пробиотиков свидетельствует о нормализующей роли пробиотиков на микробиом хозяина, снижении нейровоспаления при старении ЦНС. Выявлены задачи и перспективы будущих исследований применения пробиотиков у пациентов с когнитивными расстройствами.

\begin{tabular}{|c|c|}
\hline $\begin{array}{l}\text { ключевые слова: старение ЦНС, болезнь Аль } \\
\text { та. }\end{array}$ & \\
\hline $\begin{array}{l}\text { ВВЕДЕНИЕ } \\
\text { Согласно мнению российских демографов, } \\
\text { в среднем по миру население сохраняет довольно } \\
\text { хорошее здоровье в течение первых } 88 \% \text { времени } \\
\text { своей жизни, однако сталкивается с неблагопри- } \\
\text { ятной тенденцией ухудшения состояния здоровья } \\
\text { и снижения адаптационных возможностей } \\
\text { в «возрасте дожития» [1]. При этом высокая субъ- } \\
\text { ектная активность современного пожилого чело- } \\
\text { века является своевременным и необходимым } \\
\text { условием общего социального развития, её реали- } \\
\text { зация на индивидуальном уровне детерминирова- }\end{array}$ & $\begin{array}{l}\text { на качеством личностных и познавательных } \\
\text { свойств субъекта, что определяет особые требо- } \\
\text { вания к здоровью человека старшего возраста [2, } \\
3] \text { Интенсивное демографическое старение и рост } \\
\text { продолжительности жизни неизменно влечет за } \\
\text { собой рост возрастно-специфических медицин- } \\
\text { ских проблем: депрессивно-тревожных состоя- } \\
\text { ний, ассоциированных с соматической патологи- } \\
\text { ей, высоким суицидальным риском, когнитивные } \\
\text { расстройства }[4,5,6,7] \text {, по данным американских } \\
\text { авторов обнаруживаемые среди } 11-17 \% \text { пожилых } \\
\text { людей [8]. }\end{array}$ \\
\hline
\end{tabular}


Одной из важных особенностей когнитивных расстройств позднего возраста является их высокая коморбидность с другими психопатологическими расстройствами (аффективными, психотическими, поведенческими) и с рядом соматических заболеваний. Так типичные возрастнообусловленнные додементные когнитивные расстройства, гиппокампальные нарушения памяти оказываются следствием не только атрофическидегенеративных процессов, таких как болезнь Альцгеймера, но и децифита витаминов группы В $\left(\mathrm{B}_{1}, \mathrm{~B}_{6}, \mathrm{~B}_{12}\right)$, голодания, синдрома мальабсорбции, обусловленного различными заболеваниями желудочно-кишечного тракта [9].

Драматическое значение додементных расстройств определяется высоким риском их трансформации в деменцию, отсутствием единого понимания механизмов их становления и эффективных терапевтических подходов, позволяющих снизить этот риск. Вышеуказанное актуализирует поиск новых способов протективного воздействия на ЦНС. С появлением в последние десятилетия множества исследований на тему взаимоотношений кишечной микробиоты человека и структурно-функционального состояния ЦНС, возрос интерес к возможностям применения пробиотиков в терапии и профилактике церебральной патологии. В метаанализе, обозревающем более 300 научных публикаций за 15 лет, посвященных изучению взаимодействия кишечной микробиоты и заболеваний ЦНС, обоснована целесообразность такого интереса, представлены неоспоримые свидетельства влияния кишечной микробиоты на развитие и функционирование ЦНС на протяжении жизни, показана связь дисбактериоза кишечника с неврологическими и психическими проблемами [10]. Таким образом, существующий запрос на поиск новых способов протекции ЦНС от трансформации нормативного старения в патологическое гипотетически может помочь найти приемлемое решение в исследовании взаимодействия кишечной микробиоты и ЦНС и применения пробиотиков.

\section{ЦЕЛЬ ИССЛЕДОВАНИЯ}

Выявление возможностей использования пробиотиков в лечении заболеваний центральной нервной системы.

\section{МАТЕРИАЛ И МЕТОДЫ}

Материалом исследования явились научные публикации по теме работы. Применен общенаучный метод: анализ современной научной отечественной и зарубежной литературы по проблеме исследования, обобщение, сравнение, систематизация теоретических данных об опыте применения, оценке эффективности пробиотиков в терапии когнитивных расстройств и проявлениях их протективного действия на ЦНС.

\section{РЕЗУЛЬТАТЫ И ОБСУЖДЕНИЕ}

Теоретические предпосылки применения пробиотиков при психических расстройствах

История создания пробиотиков, по сути, сводится к развитию идеи И.И. Мечникова по целенаправленному изменению состава микрофлоры ЖКТ путем энтерального введения культур молочно-кислых бактерий в качестве антагонистов гнилостных микробов, что основывалось на доказанной Мечниковым теории «аутоинтоксикационного эффекта» комплекса кишечных микроорганизмов [11]. Первые научно обоснованные попытки использования пробиотиков для лечения многих заболеваний ЦНС предпринял американский ученый Д.Х. Келлог (1852-1943), автор ряда разработок, среди которых известно применение йогурта, вводимого с помощью клизм в прямую кишку, для лечения заболеваний ЦНС. Мотивацией к этому виду лечения послужило убеждение Д.Х. Келлога в том, что причиной множества патологических процессов в ЦНС являются токсины, вырабатываемые патогенной микрофлорой кишечника, а ряд заболеваний головного мозга, по сути, являются нейротоксическими процессами $[12,13,14]$. В 1954 г. Ф. Виржин (Ferdinand Vergina) впервые предложил термин «пробиотик» [15], хотя по другим данным [16] этот термин впервые использовали D.M. Lilly и R.H. Stillwell в 1965 г. [17] для обозначения микробных метаболитов, обладающих способностью стимулировать рост микроорганизмов. В 2002 г. рабочая группа ФАО/ВОЗ приняла определение пробиотиков (Probiotics) как живых микроорганизмов, вызывающих при применении в адекватных количествах улучшение здоровья организма хозяина и способствующих лучшей адаптации его к окружающей среде в конкретной экологической нише [18]. Основной механизм такого воздействия нормализация микробной палитры кишечника и пищеварительного тракта в целом при сохранении и/или активации синтеза и высвобождении ряда нейромодуляторов и нейротрансмиттеров глутамата, короткоцепочных жирных кислот Short-chainfattyacids (SCFA), биогенных аминов, серотонина, дофамина, гистамина и некоторых метаболитов аминокислот (гомоцистеин, ГАМК, триптофан). Эти биологически активные вещества, попадая через лимфатическую и сосудистую системы в головной мозг и преодолевая при этом гематоэнцефалический барьер, в конечном счете контролируют активность центральных нейронов, участвуя в формировании и организации структуры и функции ЦНС. Зарубежными исследователями доказана обратная связь ЦНС и микробиоты кишечника, чувствительность кишечных бактерий к информации, передаваемой головным мозгом через нейротрансмиттеры [19]. 


\section{Механизмы протективного действия пробио- тиков на ЦНС \\ В исследованиях с участием лабораторных} животных выявлено многокомпонентное влияние микробиоты на ЦНС хозяина за счет ее существенного вклада в гомеостаз микроглии, активацию тканевых макрофагов ЦНС. При временной эрадикации микробиоты свойства микроглии резко менялись, изменение состава микробиоты в эксперименте приводило к дефектности глии, а реколонизация сложной микробиоты частично восстанавливала микроглиальную структуру [20].

Данные метаанализов позволили предположить, что изменения микробиоты могут играть патофизиологическую роль при заболеваниях головного мозга, включая расстройства аутистического спектра, тревогу, депрессию, хроническую боль, хотя не ясно зависит ли психическое заболевание от общей модификации микробиоты кишечника, какова роль отдельного бактериального вида в формировании определенного патологического состояния. При этом доказано, что психологические и физические стрессоры влияют на состав и метаболическую активность микробиоты кишечника, а экспериментальные изменения микробиоты - на эмоциональное поведение и связанные с ним системы мозга [21, 22].

Отечественными и зарубежными авторами показан вклад дисфункциональной микробиоты в сложные коморбидные взаимодействия воспалительных заболеваний кишечника и ряда эндогенных психических расстройств: циклотимии, расстройств аутистического спектра, биполярных, тревожных, депрессивных и шизотипических расстройств, шизофрению [23, 24]. Выявлено, что микробиота кишечника влияет на развитие и активность мозга через нейроэндокринную, нейроиммунную и вегетативную нервные системы [25]. В 2017 г. мировому научному сообществу был представлен новый термин «маприноз» (maprinoz) - связь микробиоты с болезнями Паркинсона Альцгеймера через протеинопатию и нейровоспаление посредством участия кишечных бактерий в синтезе $\alpha$-синуклеина, при неправильной конформации которого образуются белковые агрегаты в ЦНС и развивается нейродегенеративное повреждение. Это в определенной степени поддерживает предположение о том, что болезнь Паркинсона начинается в кишечнике, а затем «перебирается» по блуждающему нерву в мозг, где разрушает дофаминергические нейроны черной субстанции [26, 27]. Усеченная ваготомия и дефицит $\alpha$-синуклеина в кишечнике предотвращали распространение $\alpha$-синуклеинопатии от кишечника к головному мозгу и связанные с этим распространением нейродегенерацию и поведенческий дефицит [28, 29, 30].
Это позволило ряду исследователей предположить, что микробиомно-опосредованная терапия может быть безопасным и эффективным методом лечения патологических состояний психоневрологического круга [31, 32]. Осознавая перспективность данного направления протекции нормативного старения ЦНС, Национальный институт психического здоровья США в 2013 г. представил программу исследования механизмов взаимодействия микробиоты и головного мозга с целью создания новых средств лечения психических расстройств в старшем возрасте [33]. В 2016 г. был опубликован список проектов направленного воздействия на микробиоту человека с целью увеличения продолжительности жизни при сохранении психического и физического здоровья и международных компаний, осуществляющих эти проекты [34].

Оценка терапевтической эффективности применения пробиотиков

Активные научные исследования проводятся в области изучения микробиоты кишечника. В настоящее время бактериологические нарушения микробиоты рассматриваются как срыв адаптационных возможностей организма, сопряженный с нарушениями в состоянии иммунной системы и клиническими проявлениями болезни. Микробиота кишечника рассматривается как основной компонент триады, способный разорвать патогенный круг развития заболевания наряду с иммунным статусом и патологическим процессом [35]. Однако современные доказательства функционирования оси «микробиота - кишечник - мозг» у человека ограничены [36]. В моделях на животных показано нарушение микробиоты кишечника при заболеваниях ЦНС, включая болезнь Паркинсона, но данные исследований на людях ограничены.

Известные исследования японских авторов определили терапевтический потенциал Bifidobacteriumbreve A1 в предотвращении когнитивных нарушений на мышиной модели болезни Альцгеймера и у пожилых пациентов с легкими когнитивными нарушениями в процессе 12недельного лечения. В представленном исследовании когнитивные функции оценивались в динамике с помощью японской версии Repeatable Battery для оценки нейропсихологического статуса (RBANS) и MMSE. Зафиксировано значительное повышение показателей тестирования при сравнении с группой плацебо при отсутствии побочных эффектов используемого лечения [37]. Отдельные клинические исследования показали, что добавление пробиотиков на основе Lactobacillus и Bifidobacterium улучшало когнитивные, сенсорные и эмоциональные функции у лиц, страдающих болезнью Альцгеймера. В эксперименте коррекция 
дисбактериоза некоторыми растительными продуктами (например, диетическими полифенолами) противодействовала начальному формированию БА независимо от активности данных полифенолов в отношении свободных радикалов или усиления реакции клеточного стресса [38].

Клинические данные показали нечувствительность когнитивных и биохимических показателей пациентов с тяжелой формой БА к пробиотическим добавкам вне зависимости от их состава и дозировки, это позволило предположить, что тяжесть заболевания определяет результативность пробиотического лечения [39]. По мнению исследователей, функциональная активность и состав микрофлоры кишечника людей пожилого и старческого возрастов не оказывают достоверного влияния на степень выраженности когнитивных нарушений, но влияют на их динамику и скорость утяжеления состояния пациента [40, $41,42]$. На фоне противоречивых данных о влиянии диет с высоким содержанием жиров на состав кишечной микрофлоры и развитие нейровоспаления сведения о благоприятном влиянии пробиотикообогащенных диет на функционирование ЦНС более однозначны. Отмечается положительное влияние 12-недельного приема пробиотиков на когнитивные функции и некоторые метаболические параметры у пациентов с БА, при этом показатели окислительного стресса, воспаления, уровень глюкозы, липидные профили не менялись [43]. Отдельными клиницистами указывается на усиление связи ожирения - метаболического синдрома - риска деменции, дисбактериоза кишечника - местного воспаления - нейровоспаления - нейродегенерации при диете с высоким содержанием жиров в рационе и снижении потребления пробиотиков [44]. В экспериментальном исследовании лабораторных животных не обнаружено достоверного влияния изменения состава кишечной микробиоты, ассоциированного с обогащенной жирами диетой, на развитие нейровоспаления, оцениваемого по состоянию микроглии, образований коры головного мозга, гиппокампа и гипоталамуса, и не выявлено негативной динамики когнитивных функций [45].

Задачи будущих исследований пробиотиков у пациентов с когнитивными расстройствами

Противоречивые данные указывают на важность методологической коррекции дальнейших как лабораторных экспериментов по изучению влияния пробиотиков на ЦНС, стандартизируя факторы возраста животной модели, продолжительности диеты, состава рациона и др., так и клинических испытаний, сосредоточенных на изучении специфических кишечных микробов или микробных метаболитов, способствующих развитию ряда конкретных заболеваний ЦНС.
Предлагается изучать анксиолитические и антидепрессивные эффекты пробиотиков в более фенотипически однородных популяциях, так как модуляция кишечной микробиоты сможет служить новой терапевтической мишенью для лечения и/или профилактики расстройств настроения и тревоги у легко когнитивно сниженных пожилых людей [46]. В плане актуализации проблемы лечения возрастно-специфических психических расстройств и последствий стресса (ПТСР, стрессовое расстройство, иные стресс-индуцированные состояния, сопровождающиеся хронической болью и расстройствами эмоций и поведения) указывается на обязательность учета сложных поведенческих паттернов и их механизмов при данных расстройствах, оценивая влияние кишечной микробиоты и ее коррекции пробиотиками [47].

Перспективы применения пробиотиков при когнитивных расстройствах позднего возраста

Представляет интерес изучение возможностей терапии когнитивных расстройств с помощью воздействия на микробиоту, меняющую свои свойства в процессе старения и на фоне множества возрастно-ассоциированных заболеваний [48]. Исследования когнитивного дефицита у лиц старшего возраста подтверждают его многофакторность за счет вовлечения разных систем головного мозга и организма в целом, что обусловливает ожидания повышения эффективности терапии при ее направленности против нескольких нейропатологических мишеней. Например, важную роль в патогенезе БА играют нейроиммунные взаимодействия с развитием воспаления, детерминирующим гибель нейронов и потерю синапсов, а также вовлечение в патогенез периферических тканей, участвующих в нейроиммуноэндокринной регуляции, посредством нейроиммунных взаимодействий в тканях головного мозга, опосредованных про- и противовоспалительными цитокинами и системой комплемента [49]. Обсуждается дисфункциональную связь в двунаправленной оси передачи сигналов между мозгом и кишечником, включая эфферентные и афферентные ветви периферической нервной системы, циркулирующие эндокринные гормоны и местные паракринные, нейрокринные и микробиотические факторы (микробные сигнальные молекулы при нейровоспалении) [50]. Роль нейровоспаления (neuroinflammation), как детерминанты нейропатологического процесса патологического старения, актуализирует понимание значения кишечной микробиоты в формировании нейродегенеративного процесса. Влияя на созревание и активацию микроглии мозга и периферических иммунных клеток, кишечная микробиота позволяет иммунной системе осуществить функцию потенциального ключевого медиатора ЦНС [51]. 
При дисбиозе микробиоты кишечника у лиц с болезнью Альцгеймера описаны детерминированные им повышенная проницаемость кишечника и системное воспаление, что приводит к когнитивным нарушениям через нервные, иммунные, эндокринные и метаболические пути, а также вовлечение в патологический процесс Tollподобных рецепторов (TLR) микроглии головного мозга, играющих важную роль во врожденной иммунной системе, распознавании патогенов микробного происхождения и инициации воспалительного процесса ЦНС. Сделан вывод, что вмешательство микробиоты кишечника или правильная модуляция TLR могут стать многообещающими профилактическими и терапевтическими стратегиями для болезни Альцгеймера [52].

Приводятся данные о способности пробиотиков восстанавливать состав микробиома кишечника и вводить полезные функции в микробные сообщества кишечника [53]. Подчеркивается важность разработки стратегий сохранения здоровой микробиоты в качестве самостоятельного подхода к профилактике возникновения и усугубления когнитивного дефекта. Безусловно, это не означает, что абсолютная нормализация микробиоты с помощью пробиотиков может явиться альтернативой современным методам терапии когнитивных расстройств. С другой стороны, целенаправленное воздействие на микробиоту оказывается существенным дополнением к классическим методам лечения патологии ЦНС, связанной с процессами нейродегенерации и нейровоспаления [54]. В настоящее время официально назначение плановой и длительной терапии пробиотиками пациентам с когнитивными нарушениями не регламентировано существующими стандартами лечения, хотя данная рекомендация присутствует в некоторых источниках, посвященных лечению возрастно-ассоциированной патологии, старческой астении, предотвращению преждевременного старения [55]. Очевидно, дальнейшие исследования по включению пробиотиков в комплексную протективную терапию, направленную на снижение прогредиентности патологического старения, являются весьма перспективным.

\section{ЗАКЛЮЧЕНИЕ}

Высокая распространенность и социальная актуальность когнитивных расстройств позднего возраста обусловливают необходимость поиска новых путей снижения риска их формирования и утяжеления. Патогенетическая многофакторность проблемы патологического старения ЦНС, современные знания о вкладе в него фактора нейровоспаления, дисфункциональность оси «микробиота - кишечник - мозг», наличие доказательств нормализующей роли пробиотиков на микробиом хозяина и протекцию ЦНС от патологического старения $[56,57]$ позволяют рассматривать пробиотики как перспективный ресурс, персонализирующий терапию. Несомненно, разрозненность объективных данных, отсутствие единого методологического подхода к исследованиям не позволяют в настоящее время рассматривать их как альтернативу классическим методам терапии, зарекомендовавшим себя на протяжении многих лет. Но речь идет не о переходе на некий новый способ лечения, а о дополнении широко известных методов с целью получения лучших, чем на сегодняшний день, результатов. Вполне обоснованными видятся подобные исследования в гериатрической психиатрии, исходя из того, что именно у представителей пожилого и старческого возрастов проблема мультиморбидности, полисистемности патологии, в том числе ЦНС и желудочно-кишечного тракта, представляется наиболее актуальной и требующей своего решения.

\section{КОНФЛИКТ ИНТЕРЕСОВ}

Авторы заявляют об отсутствии явных и потенциальных конфликтов интересов в связи с публикацией данной статьи.

\section{ИСТОЧНИК ФИНАНСИРОВАНИЯ}

Авторы сообщают об отсутствии финансирования или спонсорской помощи при проведении исследования.

\section{ЛИТЕРАТУРА/REFERENCES}

1. Попова Л.А., Зорина Е.Н. Состояние здоровья населения старшего возраста в регионе как фактор увеличения продолжительности жизни. Россия: тенденции и перспективы развития: ежегодник. Вып. 14 / РАН. Институт научной информации по общественным наукам. М., 2019; часть 2: 700-705. Popova LA, Zorina EN. The health status of the elderly population in the region as a factor in increasing life expectancy. Russia: Trends and Development Prospects: Yearbook. Issue 14 / RAS. Institute for Scientific Information for Social Sciences. Moscow, 2019; part 2: 700-705 (in Russian).

2. Семке В.Я. Исследовательские подходы к классификации пограничных и аддиктивных расстройств [Электрон. ресурс]. Медицинская психология в России: электрон. науч. журн. 2012; 2. Semke VYa. Research approaches to the classification of borderline and addictive disorders [Electronic resource]. Medical psychology in Russia: electronic scientific journal. 2012; 2 (in Russian). URL: http://medpsy.ru

3. Сиденкова А.П., Сердюк О.В. Психические расстройства позднего возраста: социальнодемографические и эпидемиологические корреляции. Уральский медицинский журнал. 2016; 8(141): 5-8. Sidenkova AP, Serdyuk OV. The mental disorders of late age: socio-demographic and epidemiological correlations. Ural Medical Journal. 2016; 8 (141): 5-8 (in Russian).

4. Гарганеева Н.П., Шахурова Н.И., Счастный Е.Д. Расстройства депрессивного спектра в позднем возрасте: общая проблема в терапевтической и психиатрической практике. Сибирский вестник 
психиатрии и наркологии. 2009;3(54): 78-83. Garganeeva N.P., Shakhurova NI, Schastnyy ED. Depression spectrum disorders in later life: a common problem in therapeutic and psychiatric practice. Siberian Herald of Psychiatry and Addiction Psychiatry. 2009; 3 (54): 78-83 (in Russian).

5. Куприянова И.Е., Семке Г.В., Галеева К.В. Депрессивные и тревожные расстройства при артериальной гипертонии (обзор иностранной литературы). Сибирский вестник психиатрии и наркологии. 2010;1(58): 48-51. Kupriyanova IE, Semke GV, Galeeva KV. Depressive and anxiety disorders in arterial hypertension (review of foreign literature). Siberian Herald of Psychiatry and Addiction Psychiatry. 2010; 1(58): 48-51 (in Russian).

6. Лебедева Е.В., Симуткин Г.Г., Счастный Е.Д., Репин А.Н., Сергиенко Т.Н. Особенности тревожнодепрессивных расстройств и суицидального поведения у пациентов пожилого и старческого возраста с хронической ишемической болезнью сердца. Суицидология. 2014; 5,2(15):69-76. Lebedeva EV, Simutkin GG, Schastnyy ED, Repin AN, Sergienko TN. Particularly disturbing, depressive disorders and suicidal behavior in patients of elderly and senile age with chronic cad. Suicidology. 2014;5,2(15): 69-76 (in Russian).

7. Сиденкова А.П. Особенности проявления тревоги у пациентов старших возрастных групп с разными типами умеренного когнитивного расстройства. Журнал неврологии и психиатрии им. СС. Корсакова. 2017; 117(11):45-50. Sidenkova AP. Characteristics of anxiety in patients of older age groups with different types of mild cognitive disorder. S.S. Korsakov Journal of Neurology and Psychiatry. 2017; 117(11):45-50 (in Russian). DOI: $10.17116 /$ jnevro201711711145-50

8. Petersen RC, Lopez O, Armstrong MJ, Getchius TSD, Ganguli M, Gloss D, Gronseth GS, Marson D, Pringsheim T, Day GS, Sager M, Stevens J, Rae-Grant A. Practice guideline update summary: Mild cognitive impairment. Report of the Guideline Development, Dissemination, and Implementation Subcommittee of the American Academy of Neurology. Neurology Jan 2018, $90 \quad$ (3) DOI: $10.1212 /$ WNL.0000000000004826

9. Преображенская И.С. Коморбидность когнитивных нарушений у пожилого пациента: анализ наиболее частых причин когнитивных нарушений в пожилом возрасте с разбором клинического случая. Эффективная фармакотерапия. Неврология. 2014; 3(20). Preobrazhenskaya IS. Comorbidity of cognitive impairment in an elderly patient: analysis of the most common causes of cognitive impairment in old age with a clinical case analysis. Effective Pharmacotherapy. Neurology. 2014; 3 (20) (in Russian).

10. Principi N, Esposito S. Gut microbiota and central nervous system development. J. Infect. 2016 Dec; 73 (6):536-546. https://doi.org/10.1016/j.jinf.2016.09.010

11. Мечников И.И. Этюды оптимизма. М.:, Наука, 1988: 328. Mechnikov II. Studies of optimism. Moscow: Publishing house Nauka, 1988: 328 (in Russian).

12. Kellogg JH. Plain Facts for Old and Young: Embracing the Natural History and Hygiene of Organic Life. Bur- lington, Iowa: IF Segner; 1887: 652. https://archive.org/details/plainfaorold00kell/page/24/m ode/2up

13. Schwarz RW. John Harvey Kellogg: Pioneering Health Reformer. Hagerstown, MD: Review \& Herald Publishing; 2006: 240.

14. Markel H. John Harvey Kellogg and the Pursuit of Wellness. JAMA. 2011 May. 305(17):1814-1815. https://doi.org/10.1001/jama.2011.557

15. Vergin F. Anti und Probiotika. Hippokrates. 1954 Feb 28; 25(4): 16-119. PMID: 13174124

16. Плотникова Е.Ю., Захарова Ю.В. Место пробиотиков в современной клинической практике. Педиатрия. Consilium Medicum. Приложение. 2018; 1: 5-99. Plotnikova EYu, Zakharova YuV. The place of probiotics in modern clinical practice. Pediatrics. Consilium Medicum. Application. 2018; 1: 95-99 (in Russian). https://doi.org/10.26442/2413-8460_2018.1.95-99

17. Lilly DM, Stillwett RH. Probiotics: Groth promoting factors produced by microorganisms. Science. 1965 Feb 12;147(3659):747-8. doi: $10.1126 /$ science. 147.3659 .747

18. FAO/WHO. Working group on drafting guidelines for the evaluation of probiotics in food. Guidelines for the evaluation of probiotics in food.2002. ftp://ftp.fao.org/es/esn/food/wgreport2.pdf

19. Pluta R, Ułamek-Koziol M, Januszewski S, Czuczwar SJ. Gut microbiota and pro/prebiotics in Alzheimer's disease. Aging (Albany NY). 2020 Mar 19;12(6):5539-5550. doi: 10.18632/aging.102930

20. Erny D, Hrabě de Angelis AL, Jaitin D, Wieghofer P, Staszewski O, David E, Keren-Shaul H, Mahlakoiv T, Jakobshagen K, Buch T. Schwierzeck V, Utermöhlen O. Chun E, Garrett W.S, McCoy KD, Diefenbach A, Staeheli P, Stecher B, Amit I, Prinz M. Host microbiota constantly control maturation and function of microglia in the CNS. Nat Neurosci. 2015 Jul;18(7):965977. https://doi.org/10.1038/nn.4030

21. Mayer EA, Knight R, Mazmanian SK, Cryan JF, Tillisch K. Gut microbes and the brain: paradigm shift in neuroscience. J. Neurosci. 2014 Nov 12;34(46): 54906. https://doi.org/10.1523/JNEUROSCI.3299-14.2014

22. Rieder R, Wisniewski P.J, Alderman B.L, Campbell S.C. Microbes and mental health: A review. Brain Behav Immun. 2017 Nov;66:9-17. https://doi.org/10.1016/j.bbi.2017.01.016

23. Ромасенко Л.В., Махов В.М., Турко Т.В., Пархоменко И.М., Исайкина М.А. Воспалительные заболевания кишечника и коморбидные психические расстройства. Российский психиатрический журнал. 2017; 6: 40-45. Romasenko LV, Makhov VM, Turko TV, Parkhomenko IM, Isaykina MA. Inflammatory bowel disease and comorbid mental disorders. Russian Psychiatric Journal. 2017; 6: 40-45 (in Russian).

24. Li Q, Han Y, Belle AC, Hagerman RJ. The Gut Microbiota and Autism Spectrum Disorders. Front Cell Neurosci. 2017 Apr 28. 11: 120. doi: 10.3389/fncel.2017.00120

25. Aslam H, Green J, Jacka FN, Collier F, Berk M, Pasco J, Dawson SL. Fermented foods, the gut and mental health: a mechanistic overview with implications for depression and anxiety. Nutr Neurosci. 2020 Sep; 3(9): 59-671. doi: 10.1080/1028415X.2018.1544332 
26. Braak H, Del Tredici K, Rüb U, de Vos RA, Jansen Steur EN, Braak E. Staging of Brain Pathology Related to Sporadic Parkinson's Disease. Neurobiol Aging. Mar-Apr 2003; 4(2):197-211. doi: 10.1016/s01974580(02)00065-9

27. Braak H, Ghebremedhin E, Rüb U, Bratzke H, Del Tredici K. Stages in the development of Parkinson's disease-related pathology. Cell Tissue Res. 2004 Oct; 18(1):121-34. doi: 10.1007/s00441-004-0956-9

28. Коротковских Л.С. Пробиотики и антибиотики в коррекции нейродегенеративных заболеваний (обзор литературы). Вестник уральской медицинской академической науки. 2019; 16(3): 465-478. Korotkovskikh LS. Probiotics and antibiotics in the correction of neurode enerative diseases (literature review). Bulletin of the Ural Medical Academic Science. 2019; 16(3): 465-478 (in Russian). https://doi.org/10.22138/25000918-2019-16-4-465-478

29. Kim S, Kwon SH, Kam TI, Panicker N, Karuppagounder SS, Lee S, Lee JH, Kim WR, Kook M, Foss CA, Shen C, Lee H, Kulkarni S, Pasricha PJ, Lee G, Pomper MG, Dawson VL, Dawson TM, Ko HS. Transneuronal Propagation of Pathologic $\alpha$-Synuclein from the Gut to the Brain Models Parkinson's Disease. Neuron. $\quad 2019$ Aug 21;103(4):627-641.e7. doi: 10.1016/j.neuron.2019.05.035

30. Sun MF, Shen YQ. Dysbiosis of gut microbiota and microbial metabolites in Parkinson's Disease. Ageing Res Rev. $2018 \quad$ Aug; 5:53-61. doi: 10.1016/j.arr.2018.04.004

31. Li Q, Han Y, Dy ABC, Hagerman RJ. The Gut Microbiota and Autism Spectrum Disorders. Front Cell Neurosci. 2017 Apr 28;11:120. doi: 10.3389/fncel.2017.00120

32. Inoue $\mathrm{T}$, Kobayashi $\mathrm{Y}$, Mori N, Sakagawa M, Xiao JZ, Moritani T, Sakane N, Nagai N. Effect of combined bifidobacteria supplementation and resistance training on cognitive function, body composition and bowel habits of healthy elderly subjects. Benef Microbes. 2018 Dec 7;9(6):843-853. doi: 10.3920/BM2017.0193

33. Шалагинова И.Г., Мацкова Л.В., Гуницева Н.М., Ваколюк И.А. Эпигенетический механизм влияния микробиоты кишечника на развитие постстрессорного нейровоспаления. Экологическая генетика. 2019; 17(4): 91-102. Shalaginova IG, Matskova LV, Gunitseva NM, Vakolyuk IA. Epigenetic mechanism of intestinal microbiota influence on the development of post-stress neuroinflammation. Ecological Genetics. 2019; 17(4): 91-102 (in Russian). https://doi.org/10.17816/ecogen17491-102

34. McDonald D, Glusman G, Price ND. Personalized nutrition through big data. Nat Biotechnol. 2016 Feb;34(2):152-4. doi: 10.1038/nbt.3476

35. Гуткевич Е.А. Методический комплекс бактериальной реконструкции микробиоты кишечника в персонифицированной медицине при первичной доврачебной помощи населению. Материалы III межрегион. научно-практ. конф. (с международным участием) / под ред. А.Н. Лукьянова. Барнаул: Изд-во: Алтайский государственный университет, 2019: 62-66. Gutkevich E.A. Methodical complex of bacterial reconstruction of intestinal microbiota in personalized medicine with primary first aid to the popu- lation. Materials of the 3rd interregional scientificpractical conference (with international participation) / edited by A.N. Lukyanov. Barnaul: Publishing House Altai State University, 2019: 62-66 (in Russian). https://www.elibrary.ru/item.asp?id=41445937

36. Quigley EMM. Microbiota-Brain-Gut Axis and Neurodegenerative Diseases. Curr Neurol Neurosci Rep. 2017 Oct 17;17(12):94. doi: 10.1007/s11910-0170802-6

37. Kobayashi Y, Kuhara T, Oki M, Xiao JZ. Effects of Bifidobacterium breve A1 on the cognitive function of older adults with memory complaints: a randomised, double-blind, placebo-controlled trial. Benef Microbes. $2019 \quad$ May 28;10(5):511-520. doi: 10.3920/BM2018.0170

38. Mancuso C, Santangelo R. Alzheimer's disease and gut microbiota modifications: The long way between preclinical studies and clinical evidence. Pharmacol Res. $2018 \quad$ Mar;129:329-336. doi: 10.1016/j.phrs.2017.12.009

39. Agahi A, Hamidi GA, Daneshvar R, Hamdieh M, Soheili M, Alinaghipour A, Esmaeili Taba SM, Salami M. Does Severity of Alzheimer's Disease Contribute to Its Responsiveness to Modifying Gut Microbiota? A Double Blind Clinical Trial. Front Neurol. 2018 Aug 15;9:662. doi: 10.3389/fneur.2018.00662

40. Claesson MJ, Cusack S, O'Sullivan O, Greene-Diniz R, de Weerd H, Flannery E, Marchesi JR, Falush D, Dinan T, Fitzgerald G, Stanton C, van Sinderen D, O'Connor M, Harnedy N, O'Connor K, Henry C, O'Mahony D, Fitzgerald AP, Shanahan F, Twomey C, Hill C, Ross RP, O'Toole PW. Composition, variability, and temporal stability of the intestinal microbiota of the elderly. Proc Natl Acad Sci U S A. 2011 Mar 15;108 Suppl 1(Suppl 1):4586-91. doi: 10.1073/pnas.1000097107

41. Суворов А.Н. Микробиология пожилых: истоки долголетия. Природа. 2017; 1:22-29. Suvorov AN. Microbiology of the elderly: the origins of longevity. Nature. 2017; 1:22-29 (in Russian)

42. Suvorov A. Gut microbiota, probiotics and human health. Biosci. Microbiota Food Health. 2013; 32(3): 81-91. https://doi.org/10.12938/bmfh.32.81

43. Akbari E, Asemi Z, Daneshvar Kakhaki R, Bahmani F, Kouchaki E, Tamtaji OR, Hamidi GA, Salami M. Effect of Probiotic Supplementation on Cognitive Function and Metabolic Status in Alzheimer's Disease: A Randomized, Double-Blind and Controlled Trial. Front Aging Neurosci. 2016 Nov 10;8:256. doi: 10.3389/fnagi.2016.00256

44. Захаров В.В., Вахнина Н.В., Громова Д.О. Когнитивные нарушения и метаболический синдром. Доктор Ру. Неврология Психиатрия. 2016; 4(121): 14-21. Zakharov VV, Vakhnina NV, Gromova DO. Cognitive impairment and metabolic syndrome. Doktor Ru. Neurology Psychiatry. 2016; 4(121): 1421 (in Russian).

45. Deshpande NG, Saxena J, Pesaresi TG, Carrell CD, Ashby GB, Liao MK, Freeman LR. High fat diet alters gut microbiota but not spatial working memory in early middle-aged Sprague Dawley rats. PLoS One. 2019 May doi: 10.1371/journal.pone.0217553 29;14(5):e0217553. 
46. Reis DJ, Ilardi SS, Punt SEW. The anxiolytic effect of probiotics: A systematic review and meta-analysis of the clinical and preclinical literature. PLoS One. 2018 Jun doi: 10.1371/journal.pone.0199041

20;13(6):e0199041.

47. Torgashov MN, Myakotnykh VS. Stress-induced pathology and accelerated aging. Adv Gerontol. 2019;32 (4): 492-501. https://doi.org/10.1134/S2079057020010142

48. Aleman FDD, Valenzano DR. Microbiome evolution during host aging. PLoS Pathog. 2019;15(7): e1007727. https://doi.org/10.1371/journal.ppat.1007727

49. Зуев В.А. Иммунологическая теория патогенеза болезни Альцгеймера: факты и гипотезы. Современные проблемы науки и образования. 2019; 4. Zuev VA. Immunological theory of pathogenesis of Alzheimer's disease: facts and hypotheses. Modern problems of science and education. 2019; 4 (in Russian). URL: http://www.scienceeducation.ru/ru/article/view?id=28961 (дата обращения: 16.08 .2020 )

50. O'Malley D. Neuroimmune Cross Talk in the Gut. Neuroendocrine and neuroimmune pathways contribute to the pathophysiology of irritable bowel syndrome. Am J Physiol Gastrointest Liver Physiol. 2016 Nov doi: 10.1152/ajpgi.00272.2016

1;311(5):G934-G941.

51. Hooper LV, Littman DR, Macpherson AJ. Interactions between the microbiota and the immune system. Science. 2012 Jun 8;336(6086):1268-73. doi: $10.1126 /$ science. 1223490

52. Lin C, Zhao S, Zhu Y, Fan Z, Wang J, Zhang B, Chen Y. Microbiota-gut-brain axis and toll-like receptors in Alzheimer's disease. Comput Struct Biotechnol J. 2019 Oct 24;17:1309-1317. doi: 10.1016/j.csbj.2019.09.008

53. Hemarajata P, Versalovic J. Effects of probiotics on gut microbiota: mechanisms of intestinal immunomodulation and neuromodulation. Therap Adv Gas- troenterol.

2013

Jan;6(1):39-51. doi: $10.1177 / 1756283 X 12459294$

54. Giau VV, Wu SY, Jamerlan A, An SSA, Kim SY, Hulme J. Gut Microbiota and Their Neuroinflammatory Implications in Alzheimer's Disease. Nutrients. 2018 Nov 14;10(11):1765. doi: 10.3390/nu10111765

55. Ильницкий А.Н., Королева М.В., Шарова А.А., Кудашкина Е.В., Коршун Е.И., Кузьминов О.М. Питание и нутритивная поддержка людей в пожилом и старческом возрасте как фактор профилактики преждевременного старения и развития гериатрических синдромов (обзор литературы). Современные проблемы здравоохранения и медицинской статистики. 2019; 3: 114-132. Ilnitskiy AN, Koroleva MV, Sharova AA, Kudashkina EV, Korshun EI, Kuzminov OM. Nutrition and nutritional support of people in advanced and old age as a factor in the prevention of premature aging and the development of geriatric syndromes (literature review). Modern Problems of Health Care and Medical Statistics. 2019; 3: 114-132 (in Russian). https://doi.org/10.24411/23122935-2019-10058

56. Toribio-Mateas M. Harnessing the Power of Microbiome Assessment Tools as Part of Neuroprotective $\mathrm{Nu}-$ trition and Lifestyle Medicine Interventions. Microorganisms. $2018 \quad$ Apr 25;6(2):35. doi: 10.3390/microorganisms6020035

57. Smith CJ, Emge JR, Berzins K, Lung L, Khamishon R, Shah P, Rodrigues DM, Sousa AJ, Reardon C, Sherman PM, Barrett KE, Gareau MG. Probiotics normalize the gut-brain-microbiota axis in immunodeficient mice. Am J Physiol Gastrointest Liver Physiol. 2014 Oct 15;307(8):G793-802. doi: 10.1152/ajpgi.00238.2014

Поступила в редакцию 02.10.2020 Утверждена к печати 30.11.2020

Мякотных Виктор Степанович, доктор медицинских наук, профессор, профессор кафедры факультетской терапии и гериатрии, профессор кафедры нервных болезней, Уральский государственный медицинский университет. Researcher ID ABH-6128-2020. Author ID Scopus 6603228052. ORCID iD https://orcid.org/00000001-9091-1390. Author ID РИНЦ 132679. SРIN-код РИНЦ 2815=1444.

Анохина Мария Валерьевна, студентка, 6-й курс, лечебно-профилактический факультет, Уральский государственный медицинский университет.

Сиденкова Алена Петровна, доктор медицинских наук, доцент, заведующая кафедрой психиатрии, психотерапии и наркологии, Уральский государственный медицинский университет. Researcher ID https://orcid.org/0000-0001-5142-3992. ORCID iD 0000-0001-5142-3992.

Сердюк Олег Викторович, главный врач ГБУЗ СО «Свердловская областная клиническая психиатрическая больница».

Мельник Алена Александровна, ординатор кафедры психиатрии, психотерапии и наркологии, Уральский государственный медицинский университет.

Сиденкова Алена Петровна, sidenkovs@mail.ru 
For citation: Myakotnykh V.S., Anokhina M.V., Sidenkova A.P., Serdyuk O.V., Melnik A.A. Advanced therapeutic approaches to cognitive disorders (the role of probiotics in complex treatment): a literature review. Siberian Herald of Psychiatry and Addiction Psychiatry. 2020; 4 (109): 73-81. https://doi.org/10.26617/1810-3111-2020-4(109)-73-81

\title{
Advanced therapeutic approaches to cognitive disorders (the role of probiotics in complex treatment): a literature review
}

\section{Myakotnykh V.S.', Anokhina M.V.', Sidenkova A.P.', Serdyuk O.V. ${ }^{2}$, Melnik A.A. ${ }^{1}$}

\author{
${ }^{1}$ Ural State Medical University \\ Street Repin, 3, 620128, Yekaterinburg, Russian Federation \\ ${ }^{2}$ Sverdlovsk Regional Clinical Psychiatric Hospital \\ Siberian tract, 8 km, 620030, Yekaterinburg, Russian Federation
}

\begin{abstract}
The article provides an overview of modern scientific domestic and foreign publications devoted to the possibilities of using probiotics in the therapy and prevention of age-specific cerebral pathology. The high prevalence of predementia cognitive disorders in the contingent of older age groups, the significant risk of their transformation into dementia, and the limited protective capabilities of classical therapeutic regimens in aggregate determine the need to search for modern assistance strategies aimed at reducing the rate of aging of the central nervous system and preventing the formation of its pathological forms. The pathogenetic multifactorial nature of the problem of patë hological aging of the central nervous system, modern knowledge about the significant contribution of neuroinflammation mechanisms to it, the dysfunctionality of the microbiota - intestine - brain axis, the potential possibility of correcting the composition of the microbiota by introducing probiotics - all this allows us to consider probiotic preparations as promising. a therapeutic resource for the prevention of cerebral pathology. Objective: to identify the possibilities of using probiotics in the prevention and treatment of diseases of the central nervous system. Research materials: scientific publications devoted to highlighting the role of probiotics in the complex treatment of cognitive disorders. A general scientific method was applied: analysis of modern scientific domestic and foreign literature on the research problem, generalization, comparison, systematization of theoretical data on the experience of use, assessment of the effectiveness of probiotic drugs in the treatment of cognitive disorders and the manifestation of their protective, CNS-oriented action. The presented analysis of the theoretical prerequisites for the use of probiotics in mental disorders, the mechanisms of the protective effect of probiotics on the brain, the therapeutic effectiveness of the use of probiotics indicates the normalizing role of probiotics on the host microbiome, and a decrease in neuroinflammation during aging of the central nervous system. The tasks and prospects of future studies of the use of probiotics in patients with cognitive disorders have been identified.
\end{abstract}

Keywords: CNS aging, Alzheimer's disease, cognitive disorders, probiotics, microbiota.

Received October 02.2020

Accepted November 30.2020

Myakotnykh Viktor S., MD, Professor, Professor of the Department of Faculty Therapy and Geriatrics, Professor of the Department of Nervous Diseases, Ural State Medical University. Researcher ID ABH-6128-2020. Author ID Scopus 6603228052. ORCID iD https://orcid.org/0000-0001-9091-1390. Author ID RSCI 132679. SPIN-код RSCI $2815=1444$.

Anokhina Maria V., student, 6th year, medical and preventive faculty, Ural State Medical University.

Sidenkova Alena P., MD, Associate Professor, Head of the Department of Psychiatry, Psychotherapy and Narcology, Ural State Medical University. Researcher ID https://orcid.org/0000-0001-5142-3992. ORCID ID 0000-0001-51423992.

Serdyuk Oleg V., Chief Physician, Sverdlovsk Regional Clinical Psychiatric Hospital.

Melnik Alena A., Resident of the Department of Psychiatry, Psychotherapy and Narcology, Ural State Medical University.

$\bowtie$ Sidenkova Alena P., sidenkovs@mail.ru 